УДК [622.464:51.001.57]:622.271.06

А.К. Судаков /д.т.н./,

Национальный технический университет «Днепровская политехника», г. Днепр, Украина

С.В. Дзюба /к.т.н./,

Институт геотехнической механики им.

Н.С. Полякова НАН Украины, г. Днепр, Украина

А.Ю. Дреус /д.т.н./, Е.Е. Лысенко /к.т.н./

Днепровский национальный университет имени Олеся Гончара, г. Днепр, Украина

\title{
МОДЕЛИРОВАНИЕ ПРОЦЕССА ЗАМОРАЖИВАНИЯ ГРАВИЙНЫХ ФИЛЬТРОВ ИСПОЛЬЗУЕМЫХ В ГОРНЫХ ТЕХНОЛОГИЯХ
}

\author{
A.K. Sudakov/Dr. Sci. (Tech.)/, \\ S.V. Dziuba /Cand. Sci. (Tech.)/,
}

A.Yu. Dreus /Dr. Sci. (Tech.)/, Ye.Ye. Lisenko /Cand.Sci. (Tech.)/
National Technical University "Dnipro

Polytechnic", Dnipro, Ukraine

Institute of Geotechnical Mechanics named by N. Poljakov of National Academy of Sciences of Ukraine, Dnipro, Ukraine

Oles Honchar Dnipro National University, Dnipro, Ukraine

\section{GRAVEL FILTERS FREEZING PROCESS SIMULATION USED IN MINING TECHNOLOGIES}

Цель. Обоснование методов математического моделирования для анализа теплофизических характеристик в технологиях использования нового типа низкотемпературных гравийных фильтров.

Методика. Анализ современных методов математического моделирования процессов тепломассообмена в гравийных фильтрах для горного производства позволил определить длительность выдержки фильтра в морозильной камере, что необходимо для обоснования энергозатрат технологии.

Результаты. Проведен анализ теплофизических аспектов технологии использования нового типа низкотемпературных гравийных фильтров. Для обеспечения надежной работы данных фильтров необходимо выполнение оценки параметров тепломассобменных процессов в теле гравийных фильтров при установке их в скважины. Представлена математическая модель для исследования тепломассопереноса в пористой среде гравийного фильтра при изготовлении его по низкотемпературной технологии и результаты расчета температурных полей в теле фильтра с учетом фазового превращения вяжущего вещества.

Научная новизна. На основе анализа современных методов математического моделирования разработана модель теплофизического процесса в теле гравийных фильтров при их установке в скважины с учетом тепло и влагопереноса в пористой среде фильтров при изготовлении их по низкотемпературной технологии.

Практическая значимость. Заключается в усовершенствованные технологий изготовления низкотемпературных гравийных фильтров, предназначенных для эксплуатачии в условиях горного производства на основе анализа полученных результатов расчета температурных полей в теле фильтра с учетом фазовых превращений вяюсщего вещества и влагопереноса.

Ключевые слова: процесс теплообмена, низкотемпературный гравийный фильтр, горные технологии, температурное поле.

DOI: 10.34185/0543-5749.2019-3-4-42-47

(С) Судаков А.К., Дзюба С.В., Дреус А.Ю., Лысенко Е.Е., 2019 г. 
Введение. Гравийные фильтры широко используются в системах подземной инфраструктуры, в частности, в скважинах подземных газовых хранилищ, системах оборотного водоснабжения, являются необходимым элементом технологического оборудования нефтяных и газовых скважин, скважин на воду, и др. [1]. В самом общем случае, технологии использования гравийных фильтров делятся на две группы. К первой группе относятся фильтры, которые изготовляются на поверхности и доставляются на забой в готовом виде. Ко второй группе относятся фильтры, которые формируются непосредственно на забое скважины. Оба подхода обладают преимуществами и недостатками при использовании их в определенных типах скважин $[2,3]$. Одной из основных проблем при использовании обеих указанных групп технологий в скважинах является процесс доставки фильтров к продуктивному горизонту, что связано с различными осложнениями и/или использованием дополнительного спускоподъемного оборудования $[4,5]$.

Для повышения эффективности технологий гравийных фильтров предлагаются разные оригинальные подходы [6]. В работе [7] предложена низкотемпературная технология изготовления гравийных фильтров, которая обладает рядом преимуществ в вертикальных скважинах по сравнению с традиционными подходами. Однако эффективность низкотемпературных фильтров зависит от тепловых условий в скважинах. Высокие температуры и гидродинамические процессы в скважинах и подземных выработках являются факторами, которые во многом ограничивают применение тех или иных технологий

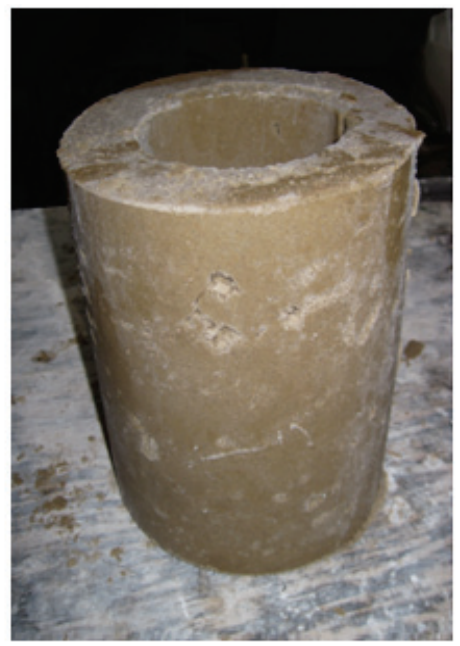

Рис. 1. Общий вид готового гравийного фильтра изготовленного по низкотемпературной технологии
[8-12], в том числе использовании гравийных фильтров [13].

Таким образом, обоснование параметров технологии по использованию низкотемпературных гравийных фильтров требует проведения специальных исследований процессов теплообмена в скважине. В качестве инструмента исследования целесообразно применять методы математического моделирования. Математическая модель процессов теплообмена процессов размораживания пористого гравийного фильтра в скважине была предложена в работе [14]. В настоящей работе рассмотрен процесс заморозки гравийного фильтра в морозильной камере при его изготовлении. Данная задача представляет интерес для оценки временных параметров низкотемпературной технологии изготовления таких фильтров и определения рациональных энергетических затрат.

Постановка задачи. Одной из основных проблем при использовании гравийных фильтров первой группы является обеспечение достаточной прочности конструкции при сохранении эффективной фильтрующей способности. В рассматриваемой низкотемпературной технологии фильтр изготовляется путем заморозки гравийной обсыпки насыщенной связывающим композитным раствором в морозильной камере. В результате получается монолит, который доставляется на забой скважины. Общий вид готового фильтра представлен на рис. 1.

При изготовлении фильтра влажный гравий засыпается в жесткую форму, после чего выдерживается в морозильной камере. Геометрическая модель представлена на рис. 2.

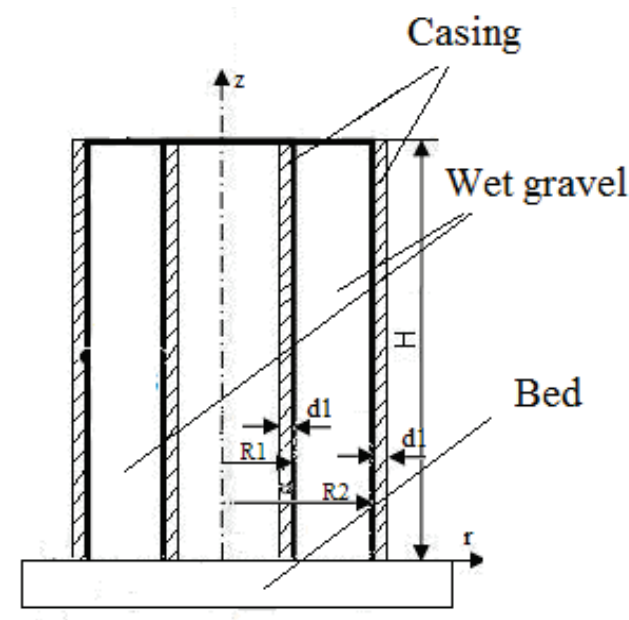

Рис. 2. Схема гравийного фильтра при изготовлении 
Рассмотрим процесс замораживания фильтра в морозильной камере. Математическая модель процессов тепло и влагопереноса в пористом теле фильтра в рамках допущений принятых в [1] имеет вид:

$$
\begin{aligned}
& c_{e f}(T, U) \rho(T) \frac{\partial T}{\partial \tau}=\frac{1}{r} \frac{\partial}{\partial r}\left(r \cdot \lambda(T, U) \cdot \frac{\partial T}{\partial r}\right)+ \\
& +\frac{\partial}{\partial z}\left(\lambda(T, U) \cdot \frac{\partial T}{\partial z}\right) \\
& \tau>0, R_{1}<r<R_{2}, 0<z<H, \\
& \left.T\right|_{\tau=0}=T_{0}, \\
& {\left[\mp \lambda_{R_{1}, R_{2}} \frac{\partial T}{\partial r}+\alpha_{R_{1}, R_{2}} T\right]_{r=R_{1}, R_{2}}=q_{R_{1}, R_{2}},} \\
& {\left[\mp \lambda_{0, H} \frac{\partial T}{\partial z}+\alpha_{0, H} T\right]_{z=0, H}=q_{0, H},} \\
& \frac{\partial U}{\partial \tau}=\frac{1}{r} \frac{\partial}{\partial r}\left(r \cdot k(T, U) \cdot \frac{\partial(1-i(T)) U}{\partial r}\right)+ \\
& +\frac{\partial}{\partial z}\left(k(T, U) \cdot \frac{\partial(1-i(T)) U}{\partial z}\right), \\
& U(r, z, 0)=U_{0}, \\
& \left.k(T, U) \frac{\partial(1-i(T)) U}{\partial r}\right|_{r=R_{1}}= \\
& =\left.k(T, U) \frac{\partial U(1-i(T))}{\partial r}\right|_{r=R_{2}}=0 \text {, } \\
& \left.k(T, U) \frac{\partial(1-i(T)) U}{\partial z}\right|_{z=0}= \\
& =\left.k(T, U) \frac{\partial(1-i(T)) U}{\partial z}\right|_{z=H}=0 .
\end{aligned}
$$

где $z, r$ - пространственные координаты, $T-$ температура, $U-$ влагосодержание, $\lambda-$ коэффициент теплопроводности, $k-$ коэффициент диффузии, $c_{e f}-$ эффективная теплоемкость, $\rho-$ плотность материала фильтра, $i-$ функция «льдистости», $R_{1}, R_{2}$ - внутренний и внешний радиусы фильтра, $H$ - высота фильтра, $\alpha-$ коэффициент теплообмена с окружающей средой, $q$ - тепловой поток.

Эффективная теплоемкость материала фильтра определяется по соотношению:

$$
\begin{gathered}
c_{e f}(T)=(1-\Pi) \cdot c_{s k}+\Pi \cdot(1-i(T)) \cdot c_{w} \cdot U+ \\
+\Pi \cdot i(T) \cdot c_{l} \cdot U \pm \frac{\rho_{l}}{\rho} \cdot \Pi \cdot L \cdot \frac{d i}{d T},
\end{gathered}
$$

где $c_{s k}, c_{w}, c_{l}$ - теплоемкости скелета, жидкости, льда, $\Pi$ - пористость фильтра, $L$ - скрытая теплота плавления льда, $\rho_{l}$ - плотность льда.

Коэффициент теплопроводности гравийной обсыпки определяем:

$$
\lambda_{f}(T)=\lambda_{m}+\left(\lambda_{t}-\lambda_{m}\right) \cdot(1-i(T)),
$$

где $\lambda_{m}$ и $\lambda_{t}$ для крупнодисперсной среды определяется эмпирическими зависимостями [15]:

$$
\begin{aligned}
& \lambda_{m}=1,7 \cdot\left(\rho \cdot 10^{-3}+0,1 \cdot U-1,1\right)-0,1 \cdot U, \\
& \lambda_{t}=1,5 \cdot\left(\rho \cdot 10^{-3}+0,1 \cdot U-1,1\right)-0,1 \cdot U .
\end{aligned}
$$

Фазовые превращения свободной воды, которая находится в поровом пространстве крупнодисперсной среды фильтра происходит в узком диапазоне температур. В этом случае функцию описывающую содержание льда в порах можно определить с использованием следующей аппроксимации [15];

$$
i(T)=\left\{\begin{array}{l}
0, T>T_{P}, \\
i_{k} \frac{1-e^{n\left(T-T_{H}\right)}}{1-e^{n\left(T_{K}-T_{H}\right)}}, T_{P} \geq T \geq T_{K}, \\
i_{k}, T<T_{K},
\end{array}\right.
$$

где $i_{k}$ - содержание льда в порах при температуре $T_{K}$, которое зависит от количества связанной влаги; $T_{H}, T_{K}-$ температуры начала и окончания фазового перехода; $n$ - коэффициент характеризующий степень связанности воды с твердым скелетом, и зависит от дисперсности, минерального и химического состава пористой среды.

Средний коэффициент теплоотдачи в период размораживания фильтра после установки его в рабочее положение определим с помощью критериального уравнения для свободной конвекции:

$$
N u_{\infty}=0,75 \cdot(G r \cdot P r)_{\infty}^{0,25} \cdot\left(\frac{P r_{\infty}}{P r_{s}}\right)^{0,25}
$$

где $N u$ - критерий Нуссельта, $P r_{\infty}, P r_{s}$ - критерии Прандтля вычисленные при температуре окружающей воды и фильтра соответственно, 
$G r=g \cdot \beta \cdot\left(T-T_{\infty}\right) \cdot H^{3} / v^{2},-$ критерий Грасгофа, $\beta$ - коэффициент теплового расширения воды, $v$ - вязкость воды, температура воды $T_{\infty}$.

Тогда средний коэффициент теплоотдачи равен:

$$
\alpha=\frac{N u_{\infty} \cdot \lambda_{\infty}}{H}
$$

где $\lambda_{\infty}$ - коэффициент теплопроводности окружающей воды при температуре $T_{\infty}$.

Результаты моделирования и их обсуждение. Задача (1)-(8) с учетом соотношений (9) - (12) решалась численно. Начальные данные были приняты следующие: $T_{P}=272 \mathrm{~K}$,

$$
\begin{aligned}
& T_{K}=273 \mathrm{~K}, \quad i_{k}=0,98 \text {, } \\
& \left.\left.c_{s k}=920 \text { Дж/(кг } \cdot \mathrm{K}\right), \quad c_{w}=4190 \text { Дж/(кг К }\right) \text {, } \\
& \left.c_{l}=2100 \text { Дж/(кг } \cdot \mathrm{K}\right), \quad \rho_{s k}=1650 \kappa \Gamma / \mathrm{M}^{3} \text {, } \\
& \rho_{w}=1000 \kappa \Gamma / \mathrm{m}^{3}, \quad \rho_{l}=920 \kappa \Gamma / \mathrm{m}^{3}, \\
& \lambda_{s k}=0,36 \mathrm{BT} /(\mathrm{M} \cdot \mathrm{K}), \quad \lambda_{w}=0,612 \mathrm{BT} /(\mathrm{M} \cdot \mathrm{K}), \\
& \lambda_{l}=2,22 \mathrm{BT} /(\mathrm{м} \cdot \mathrm{K}), \quad l=334 \text { кДж/кг. }
\end{aligned}
$$

В зависимости от выбора вида гравия коэффициент пористости находится в пределах $5 \%$ $30 \%$ (для фракций $0,5 \div 1$ мм). Геометрические размеры фильтра заданы $d_{1}=0,005 \mathrm{~m}$, $R_{1}=0,055$ м, $R_{2}=0,09$ м, $H=0,2$ м. Исходя из практических рекомендаций по изготовлению низкотемпературных гравийных фильтров, начальная температура перед заморозкой варьируется диапазоне $5 \div 25{ }^{\circ} \mathrm{C}$, в зависимости от температуры окружающей среды. Начальная влажность варьируется в диапазоне от $5 \%$ до $20 \%$. В расчетах принято, что начальная температура $15^{\circ} \mathrm{C}$, температура в морозильной камере $20{ }^{\circ} \mathrm{C}$, начальная влажность $20 \%$. Теплофизические характеристики оболочки фильтра $\lambda_{\text {cas }}=0,16 \mathrm{BT} /(\mathrm{M} \cdot \mathrm{K}), \quad c_{c a s}=1050$ Дж/(кг $\left.\cdot \mathrm{K}\right)$, $\rho_{\text {cas }}=1350$ Дж/(кг·К).

На рис. 3 представлена динамика промерзания тела фильтра в виде температурных полей в различные моменты времени от начала процесса замораживания.
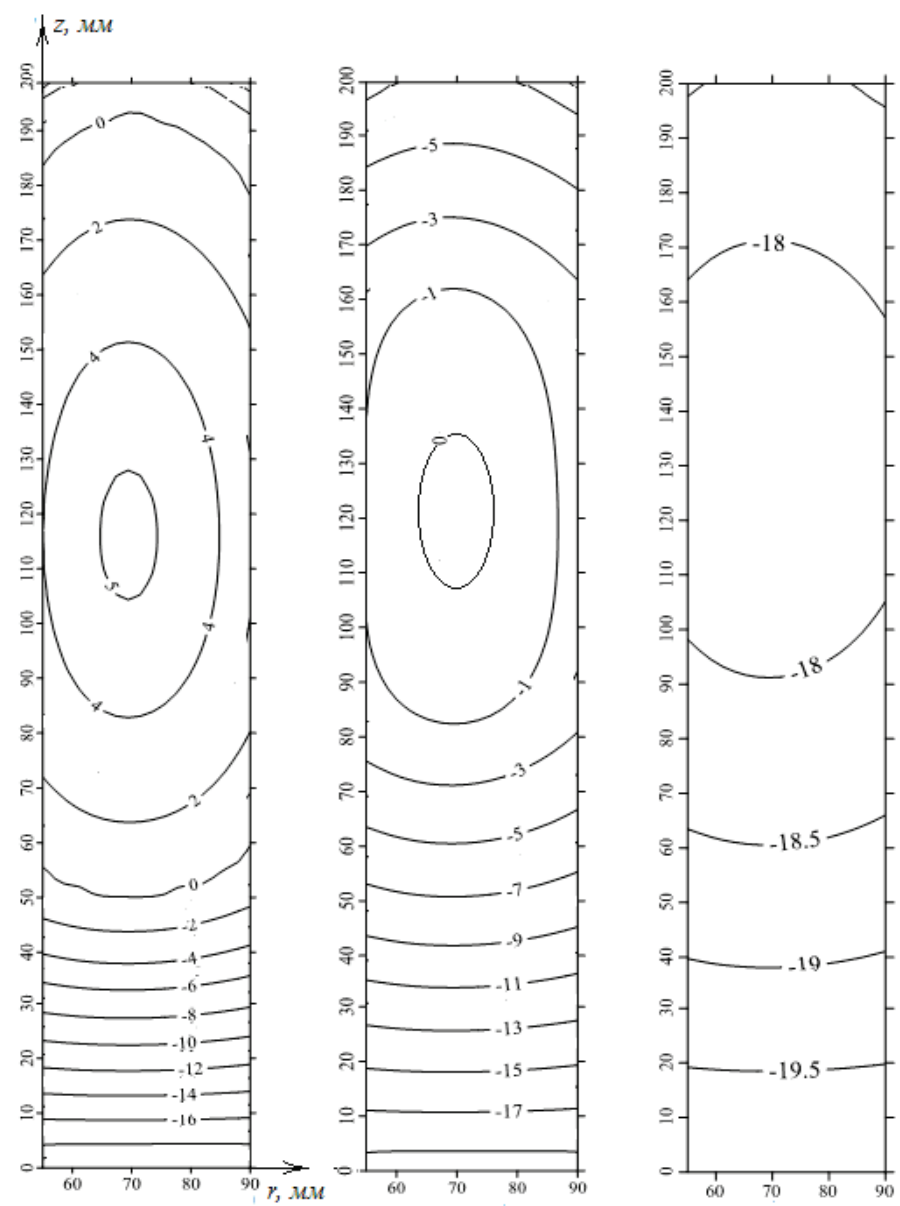

Рис. 3. Изотермы температуры $\left({ }^{\circ} \mathrm{C}\right)$ в теле гравийного фильтра при замораживании:

а) через 1 час; б) через 2 часа; в) через 7 часов 
По характеру температурных изотерм на рис. 3 видно, что через 1 час после начала процесса замораживания на верхней поверхности гравийного фильтра образуется мерзлая зона, а через 2 часа фронт фазового превращения влаги в фильтре (для воды $0{ }^{\circ} \mathrm{C}$ ) находится в середине стенки фильтра. Несимметричность распределения температурного поля объясняется различными условиями теплообмена на верхней поверхности, которая контактирует с внешней средой, и нижней поверхности, которая находится на промерзшей металлической подложке.

С технологической точки зрения, для обеспечения прочности конструкции, не обходимо получить максимально глубокую заморозку гравийного фильтра. Как видно из результатов расчета, через 7 часов после начала процесса замораживания температурные градиенты в теле фильтра незначительные. Таким образом, температурное поле выравнивается и достигает значений температуры в морозильной камере.

Выводы. Разработана математическая модель для исследования процессов тепломассобмена в пористой гравийной среде тела фильтра, который изготавливается по низкотемпературной технологии. Предложенная модель позволяет определить длительность выдержки фильтра в морозильной камере, что необходимо для обоснования энергозатрат технологии. Определены временные параметры замораживания стандартного гравийного фильтра.

\section{Библиографический список / Referernces}

1. Neal, M. R. (1983). Gravel pack evaluation. Journal of Petroleum Technology, 35(09), 1-611.

2. Dickinson, W., Anderson, R. R., \& Dykstra, H. (1987). Gravel packing of horizontal wells. SPE, 16931, 519-528.

3. Codrington, K., Nancoo-Ali, D., Leung, D., Calvert, P., Nouwens, N., \& Harris, D. (2016). A Review of Water Reduction Techniques for Open Hole Gravel Pack Completions. SPE Trinidad and Tobago Section Energy Resources Conference. Society of Petroleum Engineers.

4. Penberthy Jr., W.L. \& Echols, E.E. (1993). Gravel Placement in Wells. J Pet Technol 45 (7): 612-613, 670-674. SPE-22793-PA.

5. A. Syasev, \& T. Zelenskaya. (2016). Lengthwise movement dynamic boundary-value problem for trailing boundary ropes. Metallurgical and Mining Industry, 3, 283-287.

6. Rodrigues, R. K., Folsta, M. G., Martins, A. L., \& Sabadini, E. (2016). Tailoring of wormlike micelles as hydrodynamic drag reducers for gravelpack in oil field operations. Journal of Petroleum
Science and Engineering, 146, 142-148.

7. Kozhevnikov, A.A., Sudakov, A.K., \& Dreus, A.Yu. (2015). An Innovation Technology for Provision of Drill-Hole Equipment with Cryogenic-Gravel filters. Science and Innovation, 11 (3), 21-35. Retrieve from http://doi.org/10.15407/scine11.03.021

8. Pivnyak, G., Dychkovskyi, R, Bobyliov, O., Cabana, C.E., \& Smoliński, A. (2018). Mathematical and Geomechanical Model in Physical and Chemical Processes of Underground Coal Gasification. Solid State Phenomena, (277), 1-16. Retrieved from https://doi.org/10.4028/www.scientific.net/ SSP.277.1.

9. Sadovenko, I., Rudakov, D., \& Inkin, O. (2014). Geotechnical schemes to the multi-purpose use of geothermal energy and resources of abandoned mines. In V. Bondarenko, I.Kovalevska, K. Ganushevych (Eds.), Progressive Technologies of Coal, Coalbed Methane, and Ores Mining (pp. 443450). London, UK: Taylor \&Francis Group.

10. Cabana, E., Falshtynskyi, V., Saik, P., Lozynskyi, V., \& Dychkovskyi, R. (2018). A concept to use energy of air flows of technogenic area of mining enterprises. Ukrainian School of Mining Engineering, E3S Web of Conferences, 60, 00004. Les Ulis, France: EDP Sciences. Retrieve from https://doi.org/10.1051/e3sconf/20186000004

11. Dreus, A. Yu., \& Lysenko, K. Ye. (2016). Computer simulation of fluid mechanics and heat transfer processes at the working face of borehole rock. Naukovyi Visnyk Natsionalnoho Hirnychoho Universytetu, 5. 29-35.

12. Sudakov, A.K., Dreus, A.Yu., Khomenko O.Ye., Sudakova D.A. (2017). Analytical study of heat transfer in absorptive horizons of borehole at forming cryogenic protecting of the plugging material, Naukovyi Visnyk Natsionalnoho Hirnychoho Universytetu, 3, 38-42.

13. Prakash, C., Shroff Rama, M. (2016). Gravel Packing Fluid for High-Temperature Wells. SPE Asia Pacific Oil \& Gas Conference and Exhibition, 25-27 October, Perth, Australia SPE-182371-MS.

14. Kozhevnikov, A.A., Sudakov, A.K., Dreus, A.Yu, \& Lysenko, Ye. Ye. (2013). Study of heat transfer in cryogenic gravel filter during its transportation along a drillhole. Naukovyi Visnyk Natsionalnoho Hirnychoho Universytetu, 6, 49-54.

15. Пермяков, П.П. (1989) Идентификация параметров математической модели тепловлагопереноса в мерзлых грунтах. Новосибирск: Наука. Сиб. отд-ние, 86 с.

Permyakov, P. P. (1989) Identyfikatsiya parametriv matematychnoyi modeli teplovoho perenosa $\mathrm{v}$ merzlykh hruntakh. Novosybirsk: Nauka. Syb. otd-nya, $86 \mathrm{p}$. 
Мета. Обтрунтування методів математичного моделювання для аналізу теплофізичних характеристик в технологіях використання нового типу низькотемпературних гравійних фільтрів.

Методика. Аналіз сучасних методів математичного моделювання процесів тепломасообміну в гравійних фільтрах для гірського виробництва дозволив визначити тривалість витримки фільтра в морозильній камері, щзо необхідно для обгрунтування енерговитрат технологї.

Результати. Проведено аналіз теплофізичних аспектів технологї використання нового типу низькотемпературних гравійних фільтрів. Для забезпечення надійної роботи даних фільтрів необхідно виконання очінки параметрів тепломасобмінних процесів в тілі гравійних фільтрів при установці їх в свердловини. Представлено математичну модель для дослідження тепломасопереносу в пористому середовищі гравійного фільтра при виготовленні його з низькотемпературної технологї та результати розрахунку температурних полів в тілі фільтра з урахуванням фазового перетворення в'язкої речовини.

Наукова новизна. На основі аналізу сучасних методів математичного моделювання розроблено модель теплофізичного проиесу в тілі гравійних фільтрів при їх установці в свердловини з урахуванням тепло $i$ влагопереноса в пористому середовищі фільтрів при виготовленні їх по низькотемпературній технологї.

Практична значимість. Полягає в вдосконалені технологій виготовлення низькотемпературних гравійних фільтрів, які призначені для експлуатації в умовах гірничого виробницттва на основі аналізу отриманих результатів розрахунку температурних полів в тілі фільтру з урахуванням фазових перетворень в'язкої речовини і влагопереносу.

Ключові слова: процес теплообміну, низькотемпературний гравійний фільтр, гірничі технологіі, температурне поле.
Purpose. Mathematical modeling methods substantiation for the thermal characteristics analysis in the technologies that use a new type of low-temperature gravel filters.

Methodology. The analysis of modern methods of heat and mass transfer processes mathematical modeling in gravel filters for mining production made it possible to determine the filter exposure duration in the freezer, which is necessary to justify the technology energy consumption.

Findings. The analysis of the thermophysical aspects of technology that uses a new type of lowtemperature gravel filters has been carried out. To ensure reliable operation of these filters, it is necessary to evaluate the heat and mass transfer processes parameters in the gravel filters body when installing them in wells. A mathematical model is presented for the study of heat and mass transfer in a gravel filter porous medium during its manufacture using low-temperature technology and the calculating temperature fields results in the filter body taking into account the phase transformation of the binder.

Originality. Based on the modern methods of mathematical modeling analysis, a model of the thermophysical process in the gravel filters body has been developed when they are installed in the wells, taking into account heat and moisture transfer in the porous environment of the filters when they are manufactured using lowtemperature technology.

Practical value. Consists in improved manufacturing techniques of low-temperature gravel filters intended for operation in mining production based on the obtained results of the temperature fields calculation analysis in the filter body, taking into account the phase transformations of the binder and moisture transfer.

Key words: heat exchange process, lowtemperature gravel filter, mining technologies, temperature field.

Рукопись поступила 19.07.2019 